\title{
Preventive Use of Ascorbic Acid For Atrial Fibrillation After Coronary Artery Bypass Graft Surgery
}

\author{
Mohsen Mirmohammadsadeghi, $\mathbf{M D},{ }^{1}$ Amir Mirmohammadsadeghi, $\mathrm{MD},{ }^{1}$ Mahsa Mahmoudian, $\mathrm{MD}^{2}$ \\ ${ }^{1}$ Department of Cardiovascular Surgery, Isfahan University of Medical Sciences, Isfahan, Iran; ${ }^{2}$ Islamic Azad University, Najafabad \\ Branch, Isfahan, Iran
}

\section{ABSTRACT}

Background: Atrial fibrillation is one of the most frequent complications and a major risk of morbidity and mortality after cardiac surgery. Antioxidants such as vitamin $\mathrm{C}$ are used for prevention of this arrhythmia. Different results of studies have been reported, but most of them have shown efficiency of vitamin $\mathrm{C}$ in prophylaxis of postoperative $\mathrm{AF}$. We tried to examine this efficacy with larger sample size.

Methods: Three hundred and fourteen on pump coronary artery bypass graft surgery alone. Patients were divided into two groups: The intervention group received vita$\min \mathrm{C}(\mathrm{N}=160)$ and the control group did not receive any $(\mathrm{N}=154)$. Intervention group was administered two grams of vitamin C intravenously (IV) 24 hours preoperatively, $500 \mathrm{mg}$ every 12 hours IV for 48 hours in ICU, and $500 \mathrm{mg}$ every 12 hours PO for 48 hours in ward. Continuous monitoring in ICU and three times a day ECG was used for AF detection. The two groups were compared.

Results: The two groups were matched in terms of age, sex, LA size, ejection fraction, functional class, and TSH level. Of the patients, 244 were male. Mean age was 62 years (40-84 years) in both groups. M/F ratio was four in both groups. Functional class and ejection fraction were the same in both groups. There was no mean TSH level difference. AF occurrence in vitamin $\mathrm{C}$ group was $7.6 \%$ and in control group was $7.8 \%$. There was no difference in ICU or hospital stay.

Conclusions: Prophylactic use of vitamin $\mathrm{C}$ does not further reduce postoperative atrial fibrillation in on pump CABG patients.

\section{INTRODUCTION}

Postoperative atrial fibrillation (POAF) is one of major risks of morbidity and mortality after cardiac surgery [Mayyas 2011] and causes increased hospital stay and hospital cost [Creswell 1993; Leitch 1990; Mathew 1996; Aranki 1996; Hogue 2000; Andrews 1991; Caretta 1991]. It's prevalence is

Received November 20, 2017; accepted fune 22, 2018.

Correspondence: Amir Mirmohammadsadeghi, Cardiovascular Surgery Department, Chamran Heart Center, Moshtagh Sevvom, Isfahan, Iran; +98 9131085664 (e-mail: amirmirmohammadsadeghi@gmail.com). reported to be $10 \%$ to $65 \%$ (9) depending on age, severity of cardiac disease, comorbidity, and case complexity [Creswell 1993; Leitch 1990; Mathew 1996]. POAF usually occurs on postoperative days two to three with $70 \%$ of attacks occurring within the first four postoperative days [Mathew 1996; Aranki 1996]. About $80 \%$ of patients return to sinus rhythm within one to three days after medical treatment [Chung 2000; Ommen 1997]. Because of great burden of AF on health care resources, interest has been directed towards preventive therapy of this arrhythmia. Recent work has linked inflammation and $\mathrm{AF}$ and there is evidence that inflammation augments oxidative stress [Korantzopoulos 2003].

In addition, cardiac surgery causes acute ischemic and reperfusion injury, which leads to the release of reactive oxygen species, causing oxidative stress and a systematic inflammatory response [Laffey 2002]. Therefore prophylactic use of antioxidant vitamins, such as vitamin C, could have a protective role against oxidative stress and consequently against the onset of AF postoperatively. Sisto et al concluded that the incidence of postoperative arrhythmias, including $\mathrm{AF}$, was lower in the patients who were treated with antioxidant vitamins, including vitamin $\mathrm{C}$ and allopurinol [Sisto 1995]. Eslami et al stated that the combination of vitamin C and $\beta$-blockers may be more effective in reducing postoperative AF than $\beta$-blockers alone [Eslami 2007] In addition, as highlighted by Papoulidisa et al supplementation of vitamin $\mathrm{C}$ reduces the incidence of post coronary artery bypass graft surgery (CABG) AF, and decreases the time needed for rhythm restoration and length of hospital stay [Papoulidisa 2011]. However, other studies do not provide strong evidence for preventive role of vitamin $\mathrm{C}$ in postoperative $\mathrm{AF}$ [Carnes 2001]. In this study, we tried to evaluate vitamin $C$ effect on post $\mathrm{CABG}$ atrial fibrillation using a larger number of cases.

\section{MATERIALS AND METHODS}

This study was a randomized and double-blinded clinical trial. Patients who received vitamin C therapy (case group) were compared with patients who did not receive therapy (control group). Informed consent was obtained from each patient included in the study, and the study protocol conforms to the ethical guidelines of the 1975 Declaration of Helsinki as reflected in a prior approval by the institution's human research committee. The patient and the following nurses were not aware of the patient group; also the prescribing and 
Table 1. Patient Characteristics in Two Groups

\begin{tabular}{lccc}
\hline Characteristics & $\begin{array}{c}\text { Vitamin C Group } \\
(\mathrm{N}=160)\end{array}$ & $\begin{array}{c}\text { Control Group } \\
(\mathrm{N}=154)\end{array}$ & $P$ \\
\hline Age (mean years) & 62.1 & 62.7 & .54 \\
Age $>70$ yrs & 5 & 6 & .91 \\
Gender (male) & 128 & 116 & .44 \\
Mean TSH level (mIU/L) & 1.65 & 1.62 & .86 \\
Large LA $(>4.4 \mathrm{~cm})$ & 6 & 2 & .28 \\
Low EF $(\mathrm{EF}<40 \%)$ & 23 & 19 & .86
\end{tabular}

following nurses were different persons. Inclusion criteria were patients undergoing CABG surgery alone with preoperative sinus rhythm. Exclusion criteria were complex surgery, patient disagreement to be involved in trial, emergent surgery, history of cardiac arrhythmia or antiarrhythmic drugs, and severe renal or hepatic failure [Papoulidisa 2011; Rodrigo 2013]. Beta blockers were used routinely in ischemic patients with therapeutic indications and were not discontinued in both groups.

Three hundred and fourteen patients undergoing CABG, were included based on inclusion and exclusion criteria. The patients were divided into two groups of intervention and control (160 cases in intervention and 154 cases in the control group). Random assignment was performed by even and odd patient code.

The anaesthetic management and conduct of $\mathrm{CPB}$ were standardized. The patients were premedicated using Nitrozepam $0.1 \mathrm{mg} / \mathrm{kg}$ tablet the night of the operation, and morphine $0.15 \mathrm{mg} / \mathrm{kg}$ intramuscular half an hour before operation. Induction was done using Fentanyl 2-5 ug/kg, Propofol 1-2 mg/kg, and Pancronium $0.1 \mathrm{mg} / \mathrm{kg}$. Anaesthesia was maintained by using Sevoflurane $0.5-1 \%$, Pancronium $0.06 \mathrm{mg} / \mathrm{kg}$, Fentanyl 1-2 ug/ $\mathrm{kg}$ during cardiopulmonary bypass time.

All patients were admitted 24 hours preoperatively and operated on by a single surgical team. They underwent on pump CABG with myocardial protection using blood cardioplegia and mild hypothermia (34 C). The total $\mathrm{CPB}$, aortic cross-clamp and also reperfusion time were recorded.

Intervention group was administered two grams vitamin C intravenously (IV) 24 hours preoperatively, and postoperatively $500 \mathrm{mg}$ every 12 hours IV for 48 hours in ICU, and 500 mg every 12 hours PO for 48 hours in ward.

The primary outcome of the study was the occurrence of electrocardiographically (ECG) confirmed POAF from surgery until hospital discharge. While the patient was in ICU (at least 48 hours) constant ECG monitoring was done. In the ward ECG was done three times a day and if the patient had any new symptoms such as palpitation, dyspnea, chest pain, or weakness. If the ECG showed AF rhythm constant ECG telemetry was done for determining the duration of AF.

Analysis was done using descriptive statistics such as mean and standard deviation and analytical statistics such as T-test, Mann Whitney and Pearson and Spearman
Table 2. Comparing the results of two groups.

\begin{tabular}{lccc}
\hline Results & $\begin{array}{c}\text { Vitamin C Group } \\
(\mathrm{N}=160)\end{array}$ & $\begin{array}{c}\text { Control Group } \\
(\mathrm{N}=154)\end{array}$ & $P$ \\
\hline Postoperative stroke (\%) & 1.9 & 0.7 & 0.62 \\
Postoperative TIA (\%) & 0 & 1.3 & 0.23 \\
ICU stay (hours) & 50.4 & 52.5 & 0.39 \\
Hospital stay(days) & 8.13 & 8.22 & 0.7 \\
Atrial fibrillation (patients) & 12 & 12 & 1.0 \\
Mean AF duration (hrs) & 4.75 & 9.81 & 0.78 \\
Inotrope dependent & 37 & 39 & 0.69 \\
Intra-aortic balloon pump & 7 & 1 & 0.6
\end{tabular}

correlation coefficient by SPSS22. $P$-value $<.05$ was considered significant.

\section{RESULTS}

Both groups were matched in terms of age $(P=.542)$ and gender $(\mathrm{P}=0.441)$. The age range of patients in the intervention group was 43 years to 78 years and control group 40 years to 84 years. In intervention group, $80 \%(\mathrm{~N}=128)$ of patients were male and in control group was $75.8 \%(\mathrm{~N}=116)$. Moreover, serious adverse event were not observed in both groups (Table 1).

Furthermore, LA size, EF, and functional class did not show a significant differences between the groups $(P=.284$, $P=.846$, and $P=.279$, respectively). There was no mean TSH level difference $(P=.861)$ (Table 1$)$.

$\mathrm{AF}$ occurrence in the vitamin $\mathrm{C}$ group was $7.6 \%$ and in the control group was $7.8 \%(P=1.0)$ (Table 2).

Mean $\mathrm{AF}$ duration was 4.75 hours in the intervention group and 9.81 hours in the control group $(P=.781)$ (Table 2$)$.

The mean hospitalization time was 8.13 days in the vitamin $\mathrm{C}$ group and 8.22 days in the control group $(P=.7)$ and the mean ICU stay was 50.4 hours vs. 52.5 hours, respectively $(P=.39)$ (Table 2).

Stroke and TIA prevalence were $1.9 \%$ and $0 \%$ in the vitamin $\mathrm{C}$ group and $0.7 \%$ and $1.3 \%$ in the control group. $(P=.62$ and $P=.23$, respectively) (Table 2$)$.

Also renal insufficiency and inotrope needs and intraaortic balloon pump needs didn't show statistically significant difference (Table 2).

\section{DISCUSSION}

It is hypothesized that antioxidants may decrease the rate of postoperative atrial fibrillation. Different studies have been done on antioxidants such as vitamin $\mathrm{C}$, vitamin $\mathrm{E}$, polyunsaturated fats, and their combination to evaluate their efficacy on post cardiac surgery arrhythmia. Papoulidisa and his colleagues compared two groups of receiving and not receiving vitamin C after on pump CABG [Papoulidisa 2011]. They included 85 patients in each group and the vitamin $\mathrm{C}$ group 
received two grams of vitamin $C$ three hours prior the initiation of the cardiopulmonary bypass (CPB) and afterwards, 500 $\mathrm{mg}$ twice a day from the first postoperative day and for the next five days. They found that the vitamin C group (44.7\% vs. $61.2 \%)$ experienced significantly less postoperative atrial fibrillation $(P=.041)$ Eslami and colleagues studied the combination of beta-blockers plus vitamin $\mathrm{C}$ with beta blocker alone [Eslami 2007]. Patients in the ascorbic acid group received two grams of ascorbic acid on the night before CABG and one gram twice daily for five days after surgery. The incidence of postoperative atrial fibrillation was $4 \%$ in the ascorbic acid group and $26 \%$ in the control group $(P=.002)$.

Rodrigo and colleagues [Rodrigo 2013] included a total of 203 patients scheduled for on-pump cardiac surgery and randomized them to placebo or supplementation with n-3 polyunsaturated fatty acids (2 $\mathrm{g} /$ day) (eicosapentaenoic acid:docosahexaenoic acid ratio $1: 2)$, vitamin $\mathrm{C}$ (1 g/day), and vitamin E (400 IU/day). Postoperative atrial fibrillation occurred in 10 of 103 patients (9.7\%) in the supplemented group versus 32 of 100 patients (32\%) in the placebo group $(P<.001)$.

In this study, we tried to include a larger sample size (314) and divide them into two groups of receiving (160) and not receiving vitamin $C$ (154). Intervention group was administered 2 grams IV vitamin C 24 hours preoperatively, postoperatively $500 \mathrm{mg}$ every 12 hours IV for 48 hours in ICU, and $500 \mathrm{mg}$ every 12 hours PO for 48 hours in ward. The two groups were matched in terms of age, sex, LA size, ejection fraction, functional class, and TSH level. All operations were done by same surgical team. We found that AF occurrence in vitamin C group was $7.6 \%$ and in control group was $7.8 \%$. $(P$ $=1.0)$ Mean duration of hospital and ICU stay and postoperative TIA and CVA occurrence didn't show any significant difference. This result was different from other studies which showed obvious efficacy of vitamin $\mathrm{C}$ in reducing post CABG atrial fibrillation. Incidence of atrial fibrillation in our study was nearly the same, indicating that even a larger sample size wouldn't make any significant difference between two groups. We didn't find any obvious reason for different results of different studies.

\section{REFERENCES}

Andrews TC, Reimold SC, Berlin JA, et al. 1991. Prevention of supraventricular arrhythmias after coronary artery bypass surgery: a metaanalysis of randomized controlled trials. Circulation 84:236-244.

Aranki SF, Shaw DP, Adams DH, et al. 1996. Predictors of atrial fibrillation after coronary artery surgery: current trends and impact on hospital resources. Circulation 94:390-397.

Caretta Q, Mercanti CA, De Nardo D, et al. 1991. Ventricular conduction defects and atrial fibrillation after coronary artery bypass grafting: multivariate analysis of preoperative, intraoperative and postoperative variables. Eur Heart J 12:1107-1111.

Carnes CA, Chung MK, Nakayama T, Nakayama H, Baliga RS, Piao S, et al. 2001. Ascorbate attenuates atrial pacing-induced peroxynitrite formation and electrical remodeling and decreases the incidence of postoperative atrial fibrillation.Circ Res. 89(6):32-8.

Chung MK. 2000. Cardiac surgery: postoperative arrhythmias. Crit Care Med. 28(10): 136-144.

Creswell LL, Schuessler RB, Rosenbloom M, et al.1993. Hazards of postoperative atrial arrhythmias. Ann Thorac Surg 36:253-261.

Eslami M, Badkoubeh RS, Mousavi M, Radmehr H, Salehi M, Tavakoli N, Avadi MR. 2007. Oral ascorbic acid in combination with betablockers is more effective than beta-blockers alone in the prevention of atrial fibrillation after coronary artery bypass grafting. Tex Heart Inst J. 34(3):268-74.

Hogue CW Jr, Hyder ML. 2000. Atrial fibrillation after cardiac operations: risks, mechanisms, and treatment. Ann Thorac Surg 69:300-306.

Kern LS. 2004. Postoperative atrial fibrillation: new directions in prevention and treatment. J Cardiovasc Nurs. 19(2):103-15.

Korantzopoulos P, Kolettis T, Siogas K, Goudevenos J. 2003. Atrial fibrillation and electrical remodeling: the potential role of inflammation and oxidative stress. Med Sci Monit 9: 225-229.

Laffey JG, Boylan JF, Cheng DC. 2002. The systemic inflammatory response to cardiac surgery: implications for the anesthesiologist. Anesthesiology. 97(1):215-52

Leitch JW, Thomson D, Baird DK, et al. 1990. The importance of age as a predictor of atrial fibrillation and flutter after coronary artery bypass grafting. J Thorac Cardiovasc Surg 100:338-342.

Mathew JP, Parks R, Savino JS, et al. 1996. Atrial fibrillation following coronary artery bypass surgery: predictors, outcomes, and resource utilization. JAMA 276:300-306.

Mayyas F, Sakurai S, Ram R, et al. 2011. Dietary 3 fatty acids modulate the substrate for post-operative atrial fibrillation in a canine cardiac surgery model. Cardiovasc Res 89:852-61.

Ommen SR, Odell JA, Stanton MS. 1997. Atrial arrhythmias after cardiothoracic surgery. N Engl J Med 336:1429-1434.

Papoulidisa P, Ananiadoua O, Chalvatzoulisa E, Ampatzidoub F, Koutsogiannidisa C, Karaiskosa T, et al. 2011. The role of ascorbic acid in the prevention of atrial fibrillation after elective on-pump myocardial revascularization surgery: a single-center experience - a pilot study. Interactive CardioVascular and Thoracic Surgery 12:121-124.

Rodrigo R, Korantzopoulos P, Cereceda M, Asenjo R, Zamorano J, Villalabeitia E, et al. 2013. A Randomized Controlled Trial to Prevent PostOperative Atrial Fibrillation by Antioxidant Reinforcement. Journal of the American College of Cardiology. 62(16):1457-65.

Sisto T, Paajanen H, Metsä-Ketelä T, Harmoinen A, Nordback I, Tarkka M.1995. Pretreatment with antioxidants and allopurinol diminishes cardiac onset events in coronary artery bypass grafting. Ann Thorac Surg. 59(6):1519-23. 